\title{
Dynamic Assessment of Flood Hazard Based on Points-of-Interest Data
}

\author{
Xin $\mathrm{SU}^{\mathrm{a}}$, Weiwei SHAO ${ }^{\mathrm{a}, 1}$ and Jiahong $\mathrm{LIU}^{\mathrm{a}}$ \\ ${ }^{a}$ State Key Laboratory of Simulation and Regulation of Water Cycle in River Basin, \\ China Institute of Water Resources and Hydropower Research, Beijing 100038, China
}

\begin{abstract}
In order to better formulate flood prevention and disaster mitigation measures and reduce the impact of urban flood on social development, it is necessary to conduct a scientific and accurate flood hazard assessment. The development of big data technology has brought new opportunities for flood hazard assessment. This study used a coupling model to simulate urban flood, and used the HR method to classify flood hazard. The dynamic change process of two types of Points-of-Interest(POIs) for catering services and living services under different flood hazard degrees were counted. The results showed that (1) In the northern part of the basin, mountainous, impervious ground and the lack of effective drainage channels have combined to cause more serious floods; (2) The flood hazard were mainly low-degree in the study area. Moderate flood hazard mainly occurred in farmland and built-up land. High-degree and extreme-degree flood hazard mainly occurred on both sides of rivers in the northwest of the basin; (3) Affected by the rainfall pattern, the number of POIs affected by flood presented the characteristics of "three stages" under four flood hazard degrees; (4) The POIs of the two services was most seriously affected by the flood when the rainfall just stopped; (5) In terms of the proportion of POIs affected by floods, the impact of floods on the two industries is basically the same, but from the perspective of the number of POIs affected by floods, catering services will be more affected; (6) The spatial location of the POIs led to a slight difference in the trend of the number of POIs under high-degree and extreme-degree flood hazard. This study provided a new method for urban flood hazard dynamic assessment, which could help decision makers formulate more targeted flood prevention and disaster mitigation measures
\end{abstract}

Keywords. Urban flood, dynamic assessment, flood hazard, POIs

\section{Introduction}

Urban flooding is one of the major challenges facing the world in the 21 st century, threatening social security and the normal development of urban economy [1]. According to the statistics about the impact of flood on the economy and population, China has become one of the most affected country in the world [2]. Therefore, effective measures of flood control and disaster reduction in cities become particularly important.

\footnotetext{
${ }^{1}$ Weiwei Shao, State Key Laboratory of Simulation and Regulation of Water Cycle in River Basin, China Institute of Water Resources and Hydropower Research, Beijing 100038, China; E-mail: shaoww@iwhr.com.
} 
Scientific and accurate flood hazard assessment is the theoretical basis and premise of flood prevention and disaster reduction measures, and it is also one of the current research hotspots [3-5]. Previous research mainly focused on static assessment, assessing the loss of a certain period of time after the flood [6-8]. Few studies have focused on how losses change during flood development. If we can grasp the development process of flood loss, it will be very useful for the decision-making and deployment of flood prevention and disaster mitigation measures.

POIs is a kind of open data, which is widely used and is closely related to people's work and life [9]. Users can search for POIs according to their needs to obtain better services. People visit various POIs for various purposes, such as work, shopping, entertainment, socializing, etc. [10]. However, few studies currently use POIs data to assess urban flood damage. In order to fill this gap, this study has made some new attempts to assess the impact of flood disasters by evaluating the number of floodaffected POIs. In addition, because POIs contain location information and multiple service types, decision makers can deploy flood prevention and disaster mitigation measures in a more targeted manner.

This study presents a new method for dynamic assessment of urban flood hazard. Based on coupling model, dynamic flood inundation map was obtained. Big data techniques were used to collect POIs data in the study area. It is expected to promote the application of big data technology in the field of urban hydrology, enrich the assessment methods of urban natural hazards losses, and improve the assessment accuracy of urban natural hazards losses.

\section{Material And Methods}

\subsection{Study Area}

Qianshan River Basin is located in the crossover area of Zhongshan and Zhuhai in Guangdong Province, and it is a highly urbanized area. The total basin area is about $334 \mathrm{~km}^{2}$. Due to the special geographical location and topographical conditions, it is often subjected to flood hazards caused by typhoon surge, flood of outer river and local rainfall flood. In recent years, with the development of urbanization, the surface impervious area has been increasing, which has changed the conditions of slope runoff production and confluence and the confluence system of river network. The speed of rainfall runoff production and confluence has been accelerated, the peak value is larger, the peak time is earlier, and the water volume of waterlogging increases, which makes the flood hazard more aggravated.

\subsection{Data Sources}

In this study, six datasets were collected, including pipe network, land use, DEM, hydrological soil groups, rainfall and Points-of-Interest (POIs). The pipeline network datasets were provided by Zhuhai Institute of Urban Planning and Design. The land use was obtained by remote sensing explanation method. The remote sensing image were derived from the Gaofen-1 satellite remote sensing image of China Resources Satellite Application Center (http://www.cresda.com/CN/), with a spatial resolution of $16 \mathrm{~m}$. The DEM was derived from the ASTER GDEM digital elevation data product of the geospatial data cloud (http://slt.gd.gov.cn/shzh/), with a spatial resolution of $30 \mathrm{~m}$. The 
hydrological soil groups data was established from the Chinese soil data and classification criteria provided by the USDA. The design rainstorm under 50-year return period were calculated by using the rainstorm intensity equation in Zhuhai issued by the Zhuhai Meteorological Bureau (http:/weather.zhuhai.gov.cn), in which the peak coefficient was 0.4 , and the rainfall duration was $120 \mathrm{~min}$. The POIs data was derived from the Amap Open Platform (https://lbs.amap.com/).

\subsection{Methods}

\subsubsection{Flood Hazard Simulation}

In this study, a one-dimensional and two-dimensional coupling hydrodynamic model of urban flooding was established with water exchange as the link. The two-dimensional surface hydrodynamic process provides the flow boundary conditions for the onedimensional underground hydrodynamic process in the form of "points", which establishes the connection between the EXTRAN module and the TELEMAC-2D module. EXTRAN module serves as the calculation module of pipe network confluence, TELEMAC-2D module serves as the calculation module of rainfall runoff generation and surface confluence.

\subsubsection{Flood Hazard Classification Method}

A mathematical expression using an empirically based method is widely used to determine flood hazard rating by the Department for the Environment, Food and Rural Affairs (DEFRA) and the Environment Agency (EA) [11]. This methodology defines flood hazard rating as a combined function of flow velocity and water depth. After three stages of experimental data analysis, special topic study and standard compilation, the empirical formula of flood hazards rating and the threshold of the flood hazard ratio classifications are finally determined (table 1). The empirical formula as follows:

$$
H R=d(v+0.5)+D F
$$

Where $H R$ is the flood hazard rating $\left(\mathrm{m}^{2} / \mathrm{s}\right), d$ is the water depth $(\mathrm{m}), v$ is the velocity of the flow $(\mathrm{m} / \mathrm{s})$ and $D F$ is the debris factor $\left(\mathrm{m}^{2} / \mathrm{s}\right)$, which can have a value of $0,0.5$ or 1 , depending on water depth, velocity range and regional characteristics.

Table 1. Flood hazard classification.

\begin{tabular}{llll}
\hline HR & Degree of flood hazard & HR & Degree of flood hazard \\
\hline$<0.75$ & Low & $1.5-2.5$ & Significant \\
$0.75-1.5$ & Moderate & $>2.5$ & Extreme \\
\hline
\end{tabular}

\section{Results And Discussion}

\subsection{Urban Flood Simulation Results}

The spatial distribution of inundated depth and velocity at the 6th hour was plotted based on the simulation results for 50-year return periods, as shown in figure 1 . In the 
northern part of the basin, the inundated depth and velocity were higher. This was related to the topography and land use type of the basin. It could be seen that the floodprone areas were mainly built-up land, and the surrounding areas were mostly mountainous areas with high elevation and lack of effective drainage channels. The surrounding topography resulted in a higher flow velocity, and also caused the surrounding water to gather, but there was no effective drainage channel, so the water logging would be more serious. The inundated depth was also higher in the river, which reflected that the river channel had a good regulating effect during flood disasters and could effectively discharge flood volume.
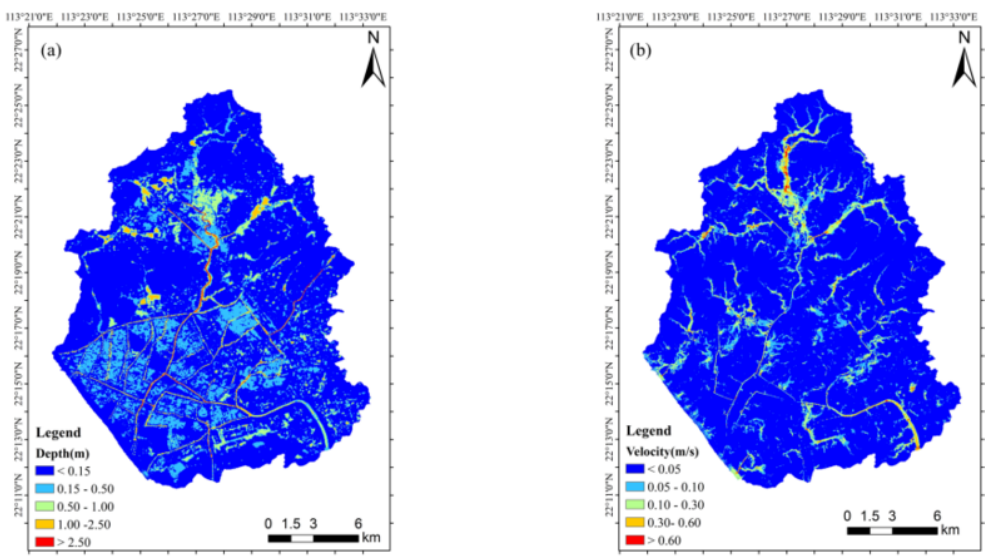

Figure 1. Spatial distribution of inundated depth and flow velocity for 50-year return period, where (a) inundated depth (b) flow velocity.

\subsection{Flood Hazard Classification Results}

The spatial distribution of flood hazard degrees at the 6th hour was plotted, as shown in figure 2. The results showed that the flood hazard in the whole study region were mainly low degree. Moderate flood hazard were mainly distributed in farmland and built-up land, these two types of land use were also closely related to human activities. Therefore, the main impact on people was the moderate flood hazard. Significant flood hazard were mainly distributed in the northwest of the basin. It could be seen from figure 2 that both the inundated depth and flow velocity in this region were larger. This was because that the region was mainly surrounded by mountainous areas, and flood in the mountainou areas would gather in this region in large quantities, but the river channels in this region lack fast drainage outlets, which leaded to more serious flood accumulation. The extreme flood hazard mainly occured along the northern and eastern river channels of the basin. Observing the topography and land use types around the river channels in these two regions, it could be found that there were urban areas on both sides of the rivers, and most of the areas outside the urban areas were mountainous areas. Therefore, under the influence of the topography, heavy rains in the mountainous areas would quickly gather downwards, while the cities were mostly impervious, so a large amount of flood would collect into the river. And there were no outlets near the river in this region, which leads to a large accumulation of flood, so the flood hazard degree in this area was the highest. 


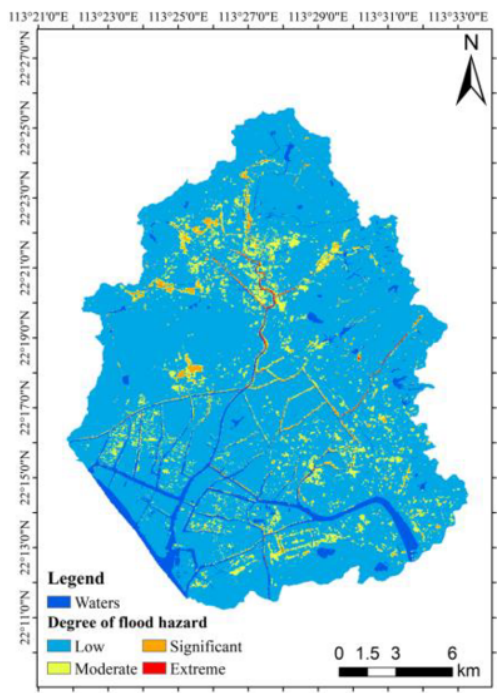

Figure 2. Spatial distribution of flood hazard degree based on HR values for 50-year return period.

\subsection{Flood Disaster Dynamic Assessment}

Dynamic changes in the number of flood-affected POIs under different flood hazard degrees were plotted, as shown in figure 3. In this study, the number of catering service POIs was 12,060, and the number of life service POIs was 6,383. Firstly, it could be seen that under four flood hazard degrees, the number of POIs affected by flood presented the characteristics of "three stages", that was, a stable period (little or almost no change), a rapid change period (increase or decrease rapidly), and a slow change period (increase or decrease slowly). This phenomenon was mainly affected by the rain pattern. Secondly, the proportion of the number of POIs affected by different flood hazard degrees at the moment of the most serious impact was calculated. For catering services, the proportions of POIs affected by flood hazard from low-degree to extremedegree were $87.89 \%, 11.00 \%, 1.02 \%$ and $0.09 \%$, respectively. For life services, the proportions of POIs affected by flood hazard from low-degree to extreme-degree were $87.71 \%, 10.90 \%, 1.25 \%$ and $0.14 \%$, respectively. For the two services, the proportion of flood-affected POIs was basically the same. It also reflected that the POIs spatial distribution of these two services was relatively consistent. Thirdly, it could be seen that as the degree of flood hazard increases, the number of flood-affected POIs also changes more drastically. Because POIs also contain location information, they also reflected that the location of high-egree flood hazard was also constantly changing, and the higher the degree, the more drastic the change. Finally, from the perspective of the dynamic changes in the number of flood-affected POIs, the most severely moment of the two services POIs affected by flood mainly occurred in the $120^{\text {th }}$ minute (catering service) and $126^{\text {th }}$ minute (life service) respectively. For catering servicethe, the number of flood-affected POIs from low degree to extreme degree was 10599, 1327, 123 and 11 respectively. For life service, the number was 5598, 696, 80 and 9 respectively. 

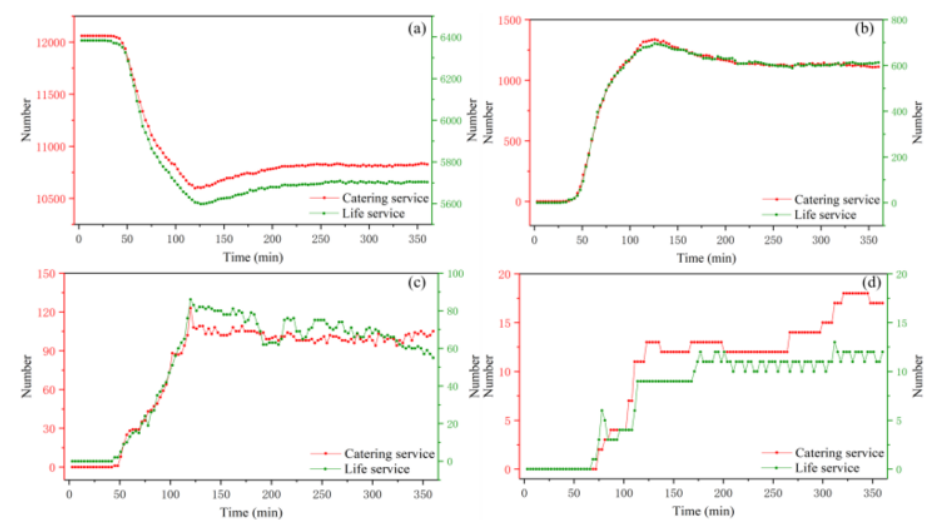

Figure 3. Dynamic changes in the number of flood-affected POIs under different flood hazard degree, where (a) - (d) represent the flood hazard degree, (a) is low degree, (b) is moderate degree, (c) is significant degree, (d) is extreme degree.

\section{Conclusions}

This study used a coupling model to simulate urban floods in highly urbanized areas. Based on the simulation results, the flood hazard degrees were classify, and the dynamic change process of the number of POIs under different flood hazard degrees were counted. The main findings were as follows:

(1) In the northern part of the basin, mountainous, impervious ground and the lack of effective drainage channels have combined to cause more serious floods;

(2) The flood hazard degrees were mainly low degree in the study area. However, moderate flood hazard mainly occured in farmland and built-up land. Therefore, the main impacts on human activities were moderate flood hazard. Due to the influence of topography, high-degree and extreme-degree flood hazard mainly occurred on both sides of the river channel in the northwest of the basin;

(3) Affected by the rain pattern, the number of POIs affected by flood presented the characteristics of "three stages" under four flood hazard degrees;

(4) From the perspective of the proportion of flood-affected POIs, the impact of floods on the two industries is basically the same, but from the perspective of the number of flood-affected POIs, the catering service will be more severely affected;

(5) The POIs of the two services was most seriously affected by the flood when the rainfall just stopped;

(6) The spatial location of the POIs led to a slight difference in the trend of the number of POIs under high-degree and extreme-degree flood hazard.

\section{Acknowledgments}

This research was funded by the Chinese National Key Research and Development Program, grant number 2018YFC1508203, Chinese National Natural Science Foundation, grant numbers 51979285, 51739011, and 51879274, Research Fund of the China Institute of Water Resources and Hydropower Research, grant numbers WR0145B502016 and 2017ZY02. 


\section{Competing Interests}

The authors have declared that no competing interests exist.

\section{References}

[1] Wu Z, Shen Y, Wang H, et al. Urban flood disaster risk evaluation based on ontology and Bayesian Network. Journal of Hydrology. 2020 Apr; 583(11):124596.

[2] Cai T, Li X, Ding X, et al. Flood risk assessment based on hydrodynamic model and fuzzy comprehensive evaluation with GIS technique. International Journal of Disaster Risk Reduction. 2019 Feb; 35(1):101077.

[3] Merz B, Kreibich H, Schwarze R, et al. Review article "Assessment of economic flood damage". Natural Hazards and Earth System Sciences. 2010 Aug; 10(8):1697-1724.

[4] Freni G, La Loggia G and Notaro V. Uncertainty in urban flood damage assessment due to urban drainage modelling and depth-damage curve estimation. Water Science and Technology. 2010 Jun; 61(12):2979-2993

[5] Jamali B, Löwe R, Bach PM, et al. A rapid urban flood inundation and damage assessment model. Journal of Hydrology. 2018 Sept; 564:1085-1098.

[6] Smith A, Bates PD, Wing O, et al. New estimates of flood exposure in developing countries using highresolution population data. Nature communications. 2019 Apr; 10(1):1-7.

[7] Raza SF, Ahsan MS and Ahmad SR. Rapid assessment of a flood-affected population through a spatial data mode. Journal of Flood Risk Management. 2017 Oct; 10(2):219-225.

[8] Mosavi A, Ozturk P and Chau K. Flood prediction using machine learning models: Literature review. Water. 2018 Oct; 10(11):1536.

[9] Gao S, Janowicz K and Couclelis H. Extracting urban functional regions from points of interest and human activities on location-based social networks. Transactions in GIS. 2017 Jun; 21(3):446-467.

[10] Li M, Kwan MP, Wang F, et al. Using points-of-interest data to estimate commuting patterns in central Shanghai, China. Journal of Transport Geography. 2018 Oct; 72:201-210.

[11] Kvočka D, Falconer RA and Bray M. Flood hazards assessment for extreme flood event. Natural Hazards. 2016 Dec; 84(3):1569-1599. 